\title{
Average of Value Derivation Technique
}

National Cancer Institute

\section{Source}

National Cancer Institute. Average of Value Derivation Technique. NCI Thesaurus. Code C81209.

The substitution of missing data with a value that represents the average of a group of specified values. 